\title{
A PROPORCIONALIDADE E A RAZOABILIDADE COMO LIMITES AO PODER ESTATAL DE CRIAR DEVERES INSTRUMENTAIS TRIBUTÁRIOS
}

\author{
THE PROPORTIONALITY AND THE REASONABILITY AS \\ LIMITS TO STATE POWER TO CREATE TAX INSTRUMENTAL \\ DUTIES
}

Marcelo Miranda Ribeiro*

\begin{abstract}
SUMÁRIO: Introdução. 1 Os deveres de colaboração com a Administração Fazendária. 2 Limites ao poder de criar deveres instrumentais tributários. $2.1 \mathrm{O}$ princípio da legalidade e os deveres instrumentais. $2.2 \mathrm{O}$ postulado da proporcionalidade. $2.3 \mathrm{O}$ postulado da razoabilidade. $2.4 \mathrm{~A}$ razoabilidade e a proporcionalidade como limites à imposição de deveres instrumentais. Conclusão. Referências.
\end{abstract}

RESUMO: O interesse pela cobrança de tributos é vital para a sociedade, pois possibilita o funcionamento regular dos serviços públicos e a consecução dos fins constitucionalmente previstos. Desse interesse nasce para o Estado o poder-dever de fiscalizar e arrecadar, em virtude do qual são impostos aos contribuintes uma grande quantidade de deveres instrumentais. Tais deveres visam a municiar a Administração com os elementos necessários para a apuração do montante tributário, criando mecanismos para impedir a sonegação tributária. Porém, se a fiscalização é um direito do Estado, não se pode permitir que esse direito perturbe o cidadão a ponto de lhe tolher o livre exercício da atividade econômica. Isso quer dizer que o direito à fiscalização e à arrecadação e a consequente imposição de deveres instrumentais encontram seus limites nos direitos individuais, devendo ser ponderados frente aos direitos fundamentais dos contribuintes. Assim, examinam-se, nesse artigo, os limites ao poder estatal de criar deveres instrumentais tributários, assim como os conflitos resultantes do uso indiscriminado desse poder e as garantias constitucionais dos contribuintes. Tais conflitos devem ser acomodados pela ponderação de princípios em face da situação fática, de maneira a proporcionar a solução mais razoável e proporcional para o caso em questão.

Palavras-chave: direitos fundamentais. poder de fiscalizar. proporcionalidade. razoabilidade.

ABSTRACT: The interest in tax collection is vital to society, because it enables the regular functioning of public services and achieve the purposes provided constitutionally. This interest rises to the State the power and duty to monitor and collect, under which are imposed on taxpayers a lot of instrumental duties. These duties are intended to equip the administration with the necessary elements for calculating the amount of taxation, creating mechanisms to prevent tax evasion. However, if the surveillance is a right of the State, can't afford that right disturb the citizen to the point of it hinders the free exercise of economic activity. This means that the right to supervision and the collection and the consequent imposition of instrumental duties find their

* Possui graduação em Informática pela Universidade Federal de Viçosa (1992) e graduação em Direito pela Universidade Federal do Paraná (2009). É especialista em Direito Processual Tributário pela CEAD/UnB e especialista em Direito Público pela Escola de Magistratura Federal do Paraná. Cursa, atualmente, o mestrado em Direito Socioambiental pela PUC/PR. É Auditor Fiscal da Receita Federal do Brasil. Tem experiência na área de Direito, com ênfase em Direito Tributário. 
limits on individual rights, should be weighed against the fundamental rights of taxpayers. Thus, will be examined in this article the limits to state power to create instrumental duties and conflicts resulting from the indiscriminate use of this power and the constitutional guarantees of taxpayers. Such conflicts must be accommodated by the weighting of principles in the face of factual situation, so as to provide the most reasonable and proportional to the case.

Keywords: fundamental rights. power of control. proportionality. reasonability.

\section{INTRODUÇÃO}

A Constituição Federal determina que são objetivos fundamentais da República Federativa do Brasil construir uma sociedade livre, justa e solidária; garantir o desenvolvimento nacional; erradicar a pobreza e reduzir as desigualdades sociais e regionais; e promover o bem de todos. Para a consecução de tais fins, obviamente, o Estado necessita de vultosos recursos financeiros.

Por isso, como destaca Ives Gandra da Silva Martins (2005, p. 673), a norma do tributo é necessária. Porém, está entre aquelas de forte rejeição social, em face de servir tanto para o Estado prestar os serviços públicos essenciais e buscar atingir seus fins, quanto para sustentar os privilégios dos detentores do poder.

Sendo, pois, uma norma antipática, observa José Casalta Nabais (2003, p. 20) que a luta eficaz contra as variadas formas de evasão fiscal constitui uma tarefa verdadeiramente titânica. No mesmo sentido, Ives Gandra da Silva Martins (2005, p. 673) entende que apenas uma fiscalização rígida permite o cumprimento da norma tributária. Afirma que o legislador garante, de um lado, os direitos dos contribuintes, mas exige que estes colaborem na determinação do fato imponível, auxiliando o Fisco na fiscalização e arrecadação de tributos.

Portanto, o interesse pela cobrança dos tributos é vital para a coletividade, pois possibilita o funcionamento regular dos serviços públicos e a consecução dos fins constitucionalmente previstos. O interesse fiscal atua, assim, como o elemento a legitimar as particularidades do Direito Tributário que, de outro modo, não encontraria justificação no ordenamento jurídico. Sob este perfil, afirma Enrico de Mita que:

[...] a particularidade do Direito Tributário não reside em sua odiosa irracionalidade, mas na predisposição de regras e institutos funcionais para o seu objetivo, o que não consiste simplesmente em impor somas a pagar, mas em fazer de modo que essas somas cheguem diligentemente aos cofres 
do Estado, para que este possa enfrentar suas próprias exigências de orçamento. (MITA, 2005, p. 253-254).

Enfim, é do interesse fiscal que nasce para o Estado o poder-dever de fiscalização tributária. Porém, faz-se mister ressalvar desde já que, se por um lado esta circunstância demanda que ao ente público se ofereça o ferramental indispensável para que ele possa dar conta de suas necessidades financeiras; por outro, opõe-se a exigência de se conferir ao contribuinte garantias em face de um ente dotado de uma tríplice função: o Estado faz a lei tributária, é destinatário de seu comando, aplica-o e julga a lide que venha a ser decorrente (MARINS, J., 2010, p. 50).

Oriundo desse poder-dever de fiscalizar e arrecadar, que conforme o exposto é de suma importância para a manutenção do Estado, são impostas ao contribuinte uma grande variedade de obrigações acessórias tributárias, que visam a facilitar a fiscalização e a evitar a evasão fiscal.

Sobre essa questão, aduz Cristiano José Ferrazzo (2006, p. 8) que é evidente que tais obrigações têm a função de municiar a Administração com os elementos necessários para a apuração do montante tributário e para a físcalização dos valores arrecadados, criando mecanismos para impedir a sonegação e a evasão tributária. Mas se a fiscalização é um direito da Administração, não se pode permitir que esse direito perturbe o cidadão a ponto de lhe tolher o livre exercício da atividade econômica ou direitos como privacidade e intimidade.

No mesmo sentido, aponta Guilherme Cezaroti que:

[...] os contribuintes brasileiros vêm sendo obrigados diariamente ao preenchimento de inúmeros documentos fiscais, que têm como objetivo primordial não incentivar a atividade empresarial, mas unicamente facilitar a fiscalização do recolhimento de tributos por parte dos diversos entes federativos. (CEZAROTI, 2008, p. 49).

Em suma, a situação fática é que a proliferação de obrigações acessórias, criadas nos mais diversos âmbitos da Administração e pelos mais diferentes órgãos, tem gerado um enorme ônus para os contribuintes.

Leve-se em conta ainda que a realidade é que tais obrigações acessórias buscam reproduzir bastante complexa, haja vista o intrincado Sistema Tributário Nacional, o que gera altos custos de conformidade às empresas em geral. Há nessa questão uma grande contradição: ao mesmo 
tempo em que o Estado é o responsável pela criação dos tributos e de seus regulamentos cada vez mais casuísticos, ele transfere ao particular a obrigação de lhe prestar todas as informações que supõe serem necessárias para uma eficiente aferição do fato gerador tributário, por meio do preenchimento de complexas obrigações acessórias.

Não bastasse isso, para facilitar ainda mais o Estado em sua tarefa "criativa" de elaboração de tais obrigações, o atual estágio do desenvolvimento tecnológico, notadamente o surgimento da Internet, lhe auxilia sobremaneira nesse trabalho. O que se vê, então, é que essas obrigações se multiplicam com o avanço da informatização e da complexidade do Sistema Tributário Nacional, alcançando, até mesmo, os pequenos municípios.

Nesse contexto, o objetivo do presente trabalho é examinar os limites ao poder estatal de criar obrigações acessórias, as quais encontram suas fronteiras nos direitos e garantias constitucionais dos contribuintes. Verificar-se-á como o conflito, porventura existente, entre os direitos individuais e o poder estatal de fiscalizar e arrecadar podem ser acomodados pela ponderação dos princípios em face da situação fática, de maneira a proporcionar a solução mais razoável e proporcional para o caso em questão.

\section{OS DEVERES DE COLABORAÇÃO COM A ADMINISTRAÇÃO FAZENDÁRIA}

A Constituição Federal estabelece o poder-dever de fiscalização do Estado no art. 145, $\S 1^{\circ}$, segunda parte, da Carta Magna, que se expressa da seguinte forma: "Sempre que possível, os impostos terão caráter pessoal e serão graduados segundo a capacidade econômica do contribuinte, facultado à administração tributária, especialmente para conferir efetividade a esses objetivos, identificar, respeitados os direitos individuais e nos termos da lei, o patrimônio, os rendimentos e as atividades econômicas do contribuinte".

Também o Código Tributário Nacional, em seus arts. 195 e 197, prescreve o dever do contribuinte, responsáveis e terceiros em colaborar com a Fazenda Pública. Igualmente, a Lei 9.784/99, que regula o processo administrativo no âmbito da Administração Pública Federal, determina, em seu art. $4^{\circ}$, que são deveres do administrado perante a Administração, entre outros, o de prestar as informações que lhe forem solicitadas e colaborar para o esclarecimento dos fatos. 
Diante dessa realidade normativa, as Fazendas Públicas têm criado diversas obrigações tributárias, normalmente, decorrentes da crescente imposição dos tributos lançados por homologação. Nesta modalidade de lançamento transfere-se ao contribuinte as funções de apurar e antecipar o montante devido, antes de qualquer manifestação por parte da Fazenda Pública, fato que leva alguns juristas a denunciar uma espécie de "privatização da gestão tributária". E os eventuais erros cometidos pelo sujeito passivo configuram descumprimento da obrigação, sendo sancionáveis na forma da lei (DERZI, 1999, p. 12).

Sobre o lançamento por homologação, observa a referida autora que:

O legislador supõe a compatibilidade de quase todos os tributos, pelo menos os mais importantes, com o lançamento por homologação (imposto sobre a renda, sobre operações de circulação de mercadorias e serviços, sobre produtos industrializados, sobre prestações de serviços das pessoas jurídicas, contribuições especiais em geral, etc), na prática realizando uma transferência do custo das atividades de gestão administrativa para o contribuinte. (DERZI, 1999, p. 13).

O procedimento inerente ao lançamento por homologação transfere ao sujeito passivo toda a responsabilidade pelo levantamento dos dados, apuração dos fatos e mesmo pela aplicação correta da lei ao caso concreto, o que supõe, inclusive, a compreensão adequada do Direito (DERZI, 1999, p. 13).

Por isso, entende José Casalta Nabais (2003, p. 20) que a administração fiscal, modernamente, deixou de ser a aplicadora das normas de imposição ou de tributação, para passar a ser a fiscalizadora do cumprimento dessas normas por parte dos particulares, sobre os quais impendem os mais diversos e onerosos deveres fiscais, principais e acessórios.

Assim, o sujeito passivo, e mesmo terceiros de alguma forma relacionados com a obrigação tributária, tem o dever de colaborar com a Administração. Em princípio, o legislador tem liberdade relativamente ampla para disciplinar e impor tais deveres, do mesmo modo que, em tese, não existe um direito de recusa do contribuinte ao cumprimento do dever. Isso porque a atividade fiscalizatória insere-se no contexto da autotutela vinculada do Estado e é instrumento do princípio do dever de 
investigação ao qual corresponde o princípio do dever de colaboração (MARINS, J., 2010, p. 204).

Porém, como dispõe o citado dispositivo constitucional, os poderes estatais de investigação encontram seus limites nos direitos individuais. Em consequência, o poder de fiscalizar e o de impor obrigações tributárias acessórias não é absoluto, devendo ser ponderado frente aos direitos fundamentais dos contribuintes.

\section{LIMITES AO PODER DE CRIAR DEVERES INSTRUMENTAIS TRIBUTÁRIOS}

A complexidade do Sistema Tributário Nacional, a evolução tecnológica e a necessidade de recursos cada vez maiores, como dito, geram uma proliferação desordenada e casuística de obrigações acessórias impostas aos sujeitos passivos, que, não raras vezes, têm que prestar a mesma informação em distintas declarações físcais.

Nessa toada, cabe verificar quais são os limites da Administração Pública à instituição de obrigações acessórias e se elas podem ser criadas por atos infralegais, com o foi, por exemplo, no caso do Sistema Público de Escrituração Digital (SPED). Ressalte-se que tal sistema é um instrumento que unifica as atividades de recepção, validação, armazenamento e autenticação de livros e documentos que integram a escrituração comercial e físcal dos empresários e das sociedades empresárias, mediante fluxo único e computadorizado de informações, tendo sido criado pelo Decreto $n^{0}$ 6.022, de 22 de janeiro de 2007, com fundamento no art. 37, inciso XXII, da CF/1988.

O Código Tributário Nacional, em seu art. 113, determina o que são as obrigações tributárias, indicando, em seu $\S 2^{\circ}$, que elas decorrem “da legislação tributária e tem por objeto as prestações, positivas ou negativas, nela previstas no interesse da arrecadação ou da fiscalização dos tributos". Em seguida, no art. 115, define o fato gerador da obrigação acessória, estabelecendo que "é qualquer situação que, na forma da legislação aplicável, impõe a prática ou a abstenção de ato que não configure obrigação principal”.

Como se vê, há, aparentemente, uma ilimitada margem de liberdade ao Fisco para a imposição dessas obrigações, haja vista que se pode criar qualquer obrigação se houver interesse da arrecadação ou da fiscalização, além do que, ao determinar que ela decorre da legislação tributária, possibilita-se sua instituição por atos infralegais. 
Contudo, há de se ressaltar que a expressão "no interesse da arrecadação ou da fiscalização" não confere poderes ilimitados à Administração. Conforme preconiza Ives Gandra da Silva Martins, a obrigação decorrente dessa autorização "deve ser sempre adequada à necessidade de controle, razão pela qual, conforme as peculiaridades inerentes ao fato tributário, sua conformação e perfil podem variar" (MARTINS, 2005, p. 672).

De todo o modo, "o interesse da arrecadação e fiscalização" é o fundamento legal de criação das obrigações acessórias. Antes, porém, de se analisar os limites à sua instituição, cabe examinar seu conceito e sua natureza jurídica.

Ensina Paulo de Barros Carvalho (2009, p. 323) que, acompanhando a obrigação tributária strictu sensu, a ordem jurídica dispõe sobre outras prestações, positivas ou negativas, consistentes num fazer ou não fazer, que não se explicam em si mesmos, preordenados que estão a facilitar o controle e a arrecadação da quantia devida do tributo.

Por isso, a expressão “obrigações acessórias” é imprópria, uma vez que elas não possuem o aspecto caracterizador dos laços obrigacionais, inexistindo nelas prestação passível de transformação em pecúnia. Elas visam tão-somente criar deveres jurídicos que os sujeitos passivos devem observar, prestando informações ao Poder Público, executando certos atos e tomando certas providências de interesse geral (CARVALHO, 2009, p. 323).

Tais deveres, ademais, não têm natureza obrigacional por faltarlhes conteúdo mensurável em valor econômico. Não são, portanto, obrigações e, ademais, nem sempre são acessórias, já que são independentes, muitas vezes, da obrigação tributária principal (CARVALHO, 2009, p. 324).

Para exemplificar a falta de acessoriedade dessas obrigações, tome-se o caso de um procedimento de fiscalização, em que são exigidos diversos documentos ao sujeito passivo fiscalizado. Finalizado o procedimento, conclui-se que o contribuinte nada deve. Não nasceu, pois, a relação jurídica obrigacional, não sendo os deveres impostos ao sujeito fiscalizado, portanto, acessórios a qualquer obrigação fiscal (CARVALHO, 2009, p. 325).

Em posição diversa, Hugo de Brito Machado (2011, p. 323-324) entende que o adjetivo "acessório" tem sentido diverso daquele do Direito privado, segundo o qual o caráter de acessoriedade significa a vinculação a outra obrigação. Diz que, no Direito Tributário, as 
obrigações acessórias não precisariam existir se não houvesse as obrigações principais. São, por isso, acessórias, já que só existem em razão das outras obrigações, ditas principais, embora não exista, necessariamente, um liame entre elas.

A despeito dessa balizada opinião, o fato é que não há, normalmente, nessas obrigações, vinculação entre o dever instrumental instituído e um tributo em específico. Volta-se, em realidade, à atividade fiscalizatória genericamente considerada. Esse, por exemplo, é o caso do SPED, que visa a controlar toda escrituração contábil das empresas, sem relação com algum tributo em específico.

Além disso, por não haver caráter obrigacional nessas prestações, nem tampouco acessoriedade, a expressão "deveres instrumentais ou formais" é preferível à expressão "obrigação acessória". São deveres, já que o seu objeto carece de patriomonialidade e são instrumentais, pois é o meio à disposição da Administração Pública para a consecução de seus intentos tributários (CARVALHO, 2009, p. 323).

Roque Carrazza (2009, p. 346), igualmente, adota a expressão "deveres instrumentais" para se referir às obrigações acessórias. Argumenta que a relação jurídica refere-se não só à obrigação tributária principal, mas também ao conjunto de deveres instrumentais (positivos ou negativos) que gravitam em torno do tributo. Completa: "É desses deveres, de índole administrativa, que a doutrina tradicional, seguindo na traça do Código Tributário Nacional, chama, impropriamente, de obrigações acessórias".

Em suma, realmente a expressão "deveres instrumentais" parece ser a mais apropriada a denominar o instituto, pois ao identificá-lo com mais clareza possibilita-se uma melhor análise de seus limites. Por tal motivo, tal expressão será utilizada nesse trabalho, designando as obrigações de fazer e não fazer impostas aos sujeitos passivos.

\subsection{O princípio da legalidade e os deveres instrumentais}

Segundo o referido art. 113 do CTN, a obrigação acessória deve estar prevista na legislação tributária. Por isso, à primeira vista, prescinde, para a sua criação, de lei em sentido formal. Assim, para que seja válida, bastaria que a obrigação acessória fosse criada por uma das espécies da legislação tributária, que, consoante o art. 96 do CTN, compreende as leis, os tratados e as convenções internacionais, os decretos e as normas complementares que versem, no todo ou em parte, 
sobre tributos e relações jurídicas a eles pertinentes. As normas complementares, por sua vez, definidas em seu art. 100, são os atos normativos expedidos pelas autoridades administrativas; as decisões dos órgãos singulares ou coletivos de jurisdição administrativa, a que a lei atribua eficácia normativa; as práticas reiteradamente observadas pelas autoridades administrativas; e os convênios que entre si celebrem a União, os Estados, o Distrito Federal e os Municípios.

Assim, numa análise literal e muito superficial dessas disposições legais, até mesmo portarias ministeriais ou práticas reiteradamente observadas pelas autoridades administrativas poderiam criar deveres instrumentais.

No entanto a questão não é tão simples assim, haja vista que o "enfrentamento da legalidade da obrigação acessória exige o devido confronto com o ordenamento constitucional sobre o tema" (FERRAZO, 2006, p. 23).

Na doutrina de Hugo de Brito Machado, é possível a fixação de deveres instrumentais por atos infralegais. Entende o autor que:

A doutrina que tenta colocar as obrigações acessórias no âmbito da legalidade estrita é, sem dúvida, respeitável, sobretudo pela intenção de reforçar as garantias do contribuinte. Não nos parece, porém, defensável em face do Código Tributário Nacional, que exclui expressamente as obrigações acessórias do princípio da legalidade estrita. No inciso III do art. 97, definindo o âmbito da legalidade estrita, refere-se apenas ao fato gerador da obrigação tributária principal, quando a simples omissão dessas qualificações específica faria com que a norma abrangesse as duas espécies. (MACHADO, 2003, p. 30).

Em sentido oposto, Roque Carrazza (2009, p. 349) afirma que "aflora com evidência translúcida" que, por injunção do princípio da legalidade, a Administração Fazendária só pode exigir deveres instrumentais criados por lei, compreendendo aqui as leis delegadas e medidas provisórias desde que, é claro, sejam editadas em obediência ao processo legislativo constitucional. Diz o autor que:

Tem-se aduzido que, ao contrário da obrigação tributária, sempre amarrada ao princípio da estrita legalidade, o dever instrumental, desde que não entre em conflito aberto com qualquer lei, pode encontrar seu fundamento de validade num decreto, numa portaria, etc. Há quem observe que são 
lídimos os deveres que promanam de atos administrativos. Com o devido acatamento, não partilhamos destas noções, boas, talvez, para o estrangeiro, mas improsperáveis em face de nosso ordenamento jurídico. Deveras, estamos convencidos de que a tese atrita com o princípio da legalidade, que domina e informa o direito tributário brasileiro. Entendemos que os decretos, portarias, os atos administrativos em geral, só podem existir para tornar efetivo o cumprimento dos deveres instrumentais criados por lei. [...] Nem se objete que os deveres instrumentais tributários são de facílimo cumprimento e que, destarte, nada obstam a que sejam veiculados por meio de atos normativos infralegais. (CARRAZZA, 2009, p. 349).

Também Paulo de Barros Carvalho (CARVALHO, 2009, p. 329) entende que os deveres instrumentais devem observar o princípio da legalidade, defendendo que somente poderão ser exigidas prestações positivas ou negativas, no interesse da arrecadação ou físcalização dos tributos, se houver lei dispondo nesse sentido.

James Marins, no mesmo sentido, entende que a referência à expressão "legislação tributária" não permite que se possa ignorar o princípio da legalidade. Segundo aponta, os atos infralegais não podem criar obrigações ou sujeições aos fiscalizados. "Os instrumentos secundários estão adstritos aos termos da lei, que determina a dimensão da interferência que pode atingir a esfera da liberdade e propriedade do fiscalizado" (MARINS, J., 2010, p. 212).

Esclarece Roque Carrazza (2009, p. 350) ainda que para cumprir seus deveres instrumentais, o contribuinte precisa mobilizar pessoal, adquirir livros, imprimir notas fiscais, possibilitar aos agentes do Fisco o exame de sua documentação, e assim por diante. Tais providências demandam tempo e dinheiro. Além disso, pelo fato de o descumprimento dos deveres formais resolver-se em sanções de diversas espécies, inclusive pecuniárias, "repugna ao senso jurídico que uma pessoa possa pagar multa com base no não acatamento de um dever criado por norma jurídica infralegal".

Por esses motivos, o autor não admite que a Administração Tributária indique os elementos essenciais dos deveres instrumentais tributários, pois isso seria o mesmo que lhes atribuir status de legislador, o que, sem dúvida, é impossível. Em síntese, sustenta que "os cidadãos não podem ter sua esfera de liberdade restringida, vale dizer, não podem ser compelidos a qualquer comportamento, positivo ou negativo, senão 
por meio de lei" (CARRAZZA, 2009, p. 351).

Porém, não é essa a realidade do sistema tributário brasileiro. Diversos deveres formais têm sido criados com base no art. 16 da Lei ${ }^{\circ}$ 9.779/99, enquanto as penalidades por seu descumprimento estão previstas, de modo igualmente genérico, no art. 57 da Medida Provisória 2.158-35, de 24 de agosto de 2001.

Ressalte-se, todavia, que na citada Medida Provisória nenhum dever é instituído e tampouco há a previsão de qualquer conduta específica. A Lei $n^{\circ}$ 9.779/99, à qual o art. 57 remete, também não o faz. Existe, assim, uma delegação genérica na criação da penalidade, de modo que a cominação está incompleta, e como tal, não pode ser imposta (FERRAZO, 2006, p. 52). Aliás, a redação da Lei 9.799/99 deixa claro que houve uma delegação do poder de instituição de obrigações acessórias à Secretaria da Receita Federal, o que, por certo, afronta o princípio da legalidade.

À vista do exposto, Cristiano José Ferrazo (2006, p. 54), posição que acompanho, entende que os contornos mínimos da obrigação acessória devem ser criados por lei, de forma específica para cada situação, relegando para o regulamento e atos dos órgãos fiscalizadores a fixação de seus elementos técnicos.

Ocorre, porém, que o entendimento dos Tribunais tem sido diverso. O Superior Tribunal de Justiça, apenas para exemplificar como se posiciona a jurisprudência dominante, em julgamento de validade da criação da Declaração de Informações sobre Atividades Imobiliárias pela Instrução Normativa SRF 304/2003, bem como da imposição de multa pelo descumprimento da obrigação, decidiu que não cabe falar em falta de previsão legal:

TRIBUTÁRIO. DIMOB. MANDADO DE SEGURANÇA. OBRIGAÇÃO ACESSÓRIA. LEGALIDADE. DENÚNCIA ESPONTÂNEA. IMPOSSIBILIDADE. NATUREZA NÃO CONFISCATÓRIA. IRRETROATIVIDADE. 1. Não há necessidade da lei em sentido estrito para o estabelecimento de obrigação acessória, porque elas não limitam a liberdade do contribuinte, tampouco operam ingerência sobre o seu patrimônio. [...] 2. Quanto à eventual aplicação de multa pelo descumprimento de obrigação acessória, necessária é a previsão legal, conforme artigo $5^{\circ}$, II, da $\mathrm{CF}$ e o inciso $\mathrm{V}$ do artigo 97 do CTN. Na espécie dos autos, os arts. $3^{\circ}$, incisos I e II, e $4^{\circ}$ da Instrução Normativa SRF n. ${ }^{\circ} 304 / 2003$ 
- ao reproduzirem ipsis literis a punição prevista no artigo 57 da Medida Provisória n. ${ }^{\circ}$ 2.158/01 - impõem pena de multa ao descumprimento da obrigação acessória instituída conforme a permissão do artigo 16 da Lei n. ${ }^{\circ}$ 9.779/99. Não é necessário que o art. 57 da MP 2158/01 - para observar o princípio da legalidade - descreva, além da pena, a conduta (fato típico) a ser sancionada, isso porque a Lei 9.779/99 já delegou ao regulamento a instituição de obrigações acessórias (Não poderia o legislador prever todas as condutas administrativas do contribuinte que devem ser observadas para a fiel fiscalização e cobrança dos tributos). Portanto, além de lógico, é razoável e proporcional que a Lei também fixe apenas a pena para o caso de descumprimento de obrigação acessória definida em regulamento. (STJ, DJ 17/05/2010, RE 1.145.525/SC, Rel. Ministra Eliana Calmon).

Enfim, o princípio da legalidade, que seria o primeiro e mais claro limite à imposição desordenada de deveres instrumentais, como visto, tem sido desrespeitado pelo Executivo, com a complacência do Poder Judiciário, de modo que, pelo menos por enquanto, ele não é um limite efetivo à criação de deveres instrumentais.

\subsection{O postulado da proporcionalidade}

Na lição de Humberto Ávila (2008, p. 424), a proporcionalidade e a razoabilidade não funcionam como princípios ou regras, mas como normas que orientam a aplicação de princípios ou regras. Portanto, tais valores não se situam no nível das normas objeto de aplicação, mas num metanível, fornecendo critérios para aplicação de outras normas. Daí serem classificadas como postulados pelo autor.

Diversos outros autores, entretanto, classificam os referidos valores como princípios, outros como sub-princípios e outros, ainda, como cânones hermenêuticos. Contudo, como muito bem observa Rogério Leite Lobo (2005, p. 251), chame-se-os de princípios, de critérios de interpretação ou de postulados normativos de aplicação do direito, o fato é que a razoabilidade e a proporcionalidade assumem inegável relevância prática no ato de ponderação de valores de estirpe constitucional postos em confronto na solução de litígios concretos.

De todo o modo, seguindo a linha de raciocínio de Humberto Ávila a razoabilidade e a proporcionalidade serão considerados como 
postulados.

No que toca à analise da proporcionalidade, cabe ressaltar, inicialmente, que ele atua como limite à discricionariedade administrativa. Na lição de Gilmar Mendes (2001, p. 1), o conceito de discricionariedade traduz, a um só tempo, as ideias de liberdade e limitação. Reconhece-se ao legislador e ao administrador o poder de conformação dentro de limites estabelecidos pela Constituição. Veda-se, porém, o excesso de poder, o qual configura a afirmação da censura judicial no âmbito da discricionariedade legislativa ou administrativa.

$\mathrm{Na}$ lição do referido autor, a doutrina identifica como típica manifestação do excesso de poder "a violação ao princípio da proporcionalidade ou da proibição de excesso, que se revela mediante contraditoriedade, incongruência e irrazoabilidade ou inadequação entre meios e fins" (MENDES, 2001, p. 2).

Embora Gilmar Mendes tenha afirmado que um dos critérios para se avaliar a proporcionalidade é avaliar a sua razoabilidade entre meios e fins, o fato é que tais valores ensejam análises distintas na aferição da validade de uma norma ou de uma ato executivo concreto.

Explica Humberto Ávila (2008, p. 403), por sua vez, que a proporcionalidade "se estrutura na ideia de que os direitos fundamentais, ainda que possam ser restringíveis, não podem ser atingidos no seu núcleo essencial". Esse núcleo é definido como aquela parte do conteúdo de um direito sem a qual ele perde a sua mínima eficácia e, por isso, deixa de ser reconhecível como um direito fundamental.

A ideia que o postulado da proporcionalidade enuncia é a de que o ato estatal seja exarado "na extensão e intensidade proporcional ao que seja realmente necessário para o cumprimento da finalidade a que está atrelada" (CEZAROTI, 2008, p. 55).

Tal postulado informa, pois, toda a Administração Pública, bastando que exista uma relação de causalidade entre um meio e um fim colimado. A proporcionalidade tem, pois, grande relevo prático, já que a Administração Tributária está obrigada a escolher, entre as medidas adequadas para o atingimento de um dado fim, aquela que menos restringe os direitos dos contribuintes, ou seja, as vantagens jurídicas devem superar as desvantagens provocadas pela adoção da medida (ÁVILA, 2008, p. 414).

Para a completa avaliação da proporcionalidade são três os exames a serem providenciados: adequação, necessidade e proporcionalidade em sentido estrito (ÁVILA, 2008, p. 414). 
A necessidade consiste em verificar dentre as medidas disponíveis e igualmente eficazes para atingir um fim, qual é a menos gravosa em relação aos direitos atingidos. Nesse sentido, Humberto Ávila afirma que:

O exame da necessidade envolve a verificação da existência de meios que sejam alternativos àquele inicialmente escolhido pelo Poder Legislativo ou Poder Executivo e que possam promover igualmente o fim sem restringir, na mesma intensidade, os direitos fundamentais afetados. (ÁVILA, 2008, p. 420).

Duas são, assim, as verificações relativas à necessidade: primeiramente, verificar se os meios alternativos promovem igualmente $o$ fim; em segundo lugar, o exame do meio menos restritivo, ou seja, verificar se os meios alternativos restringem em menor medida os direitos fundamentais colateralmente afetados (ÁVILA, 2008, p. 420).

O segundo aspecto para a verificação da proporcionalidade é o da adequação, isto é, analisar se o meio imposto é apropriado para atingir o fim ao qual se propõe. A "adequação exige uma relação empírica entre o meio e o fim: o meio deve levar à realização do fim" (ÁVILA, 2008, p. 414).

Por fim, deve ser proporcional em sentido estrito, isto é, proíbe-se o excesso, devendo as prestações limitar-se ao suficiente para atingir os fins colimados. Tal critério revela, portanto, uma necessidade de ponderação entre o meio adotado e a limitação sofrida pelo indivíduo em parcela juridicamente protegida.

$\mathrm{Na}$ definição de Virgílio Afonso da Silva (2002, p. 40), a proporcionalidade em sentido estrito "consiste em um sopesamento entre a intensidade da restrição ao direito fundamental atingido e a importância da realização do direito fundamental que com ele colide e que fundamenta a adoção de medida restritiva".

Desse modo, para que uma medida seja considerada desproporcional em sentido estrito, basta que os motivos que fundamentam a adoção da medida não tenham peso suficiente para justificar a restrição ao direito fundamental atingido. É possível, por exemplo, que essa restrição seja pequena, bem distante de implicar a não realização de algum direito. Porém, se a importância da realização do direito fundamental, no qual a limitação se baseia, não for suficiente para justificá-la, será ela desproporcional (SILVA, 2002, p. 41).

Contudo, apesar do postulado da proporcionalidade, latu sensu, 
poder ser avaliável nos seus três elementos, ressalta Humberto Ávila que ele é de muito difícil avaliação. A dificuldade reside no fato de que os meios diferem entre si na promoção do fim. Isso porque, uns promovem mais rapidamente, outros mais vagarosamente; uns com menos dispêndios, outros com mais gastos; uns mais certos, outros mais incertos; uns são mais simples, outros mais complexos; uns são mais fáceis, outros mais difíceis, e assim sucessivamente (ÁVILA, 2008, p. 420).

Em consequência, como escolher entre um meio que restringe pouco um direito fundamental, mas, em contrapartida, promove pouco o fim, e um meio que promove bastante o fim, mas, em compensação, causa muita restrição a um direito fundamental? A ponderação entre o grau de restrição e o de promoção é inafastável, ou seja, as vantagens causadas pela promoção dos fins devem ser proporcionais às desvantagens causadas pela adoção do meio (ÁVILA, 2008, p. 420).

Enfim, o exame da proporcionalidade é bastante complexo, haja vista que a avaliação daquilo que será considerado como vantagem e como desvantagem depende de um exame fortemente subjetivo. Normalmente, um meio é empregado para atingir uma finalidade pública, relacionada ao interesse coletivo (proteção do meio ambiente, consumidores), e sua adoção causa, como efeito colateral, restrição a direitos fundamentais do cidadão (ÁVILA, 2008, p. 420).

Sobre tal questão, Humberto Ávila (2008, p. 421) defende que se não for possível avaliar a proporcionalidade de uma imposição estatal, em virtude da dificuldade de se comparar todos os meios em todos os seus aspectos, "deve-se respeitar a escolha da autoridade competente, afastando-se o meio se ele for manifestamente menos adequado que outro".

Outro importante aspecto a ser observado no exame da proporcionalidade é que, como revela Gilmar Mendes (2001, p. 4), na prática, adequação e necessidade não têm o mesmo peso ou relevância no juízo de ponderação. Para o autor, apenas o que é adequado pode ser necessário, mas o que é necessário não pode ser inadequado. Portanto, a prova da necessidade tem maior relevância do que o teste da adequação, de modo que positivo o teste da necessidade, não há de ser negativo o teste da adequação. Por outro lado, se o teste quanto à necessidade revelar-se negativo, o resultado positivo do teste de adequação não mais poderá afetar o resultado definitivo ou final.

No mesmo sentido, Virgílio Afonso da Silva (2002, p. 34) 
argumenta que a "análise da adequação precede a da necessidade, que, por sua vez, precede a da proporcionalidade em sentido estrito". Para o autor, a importância dessa ordem fica patente quando se tem em mente que a aplicação da regra da proporcionalidade nem sempre implica a análise de todas as suas três sub-regras. Entende que o juiz, nem sempre, deve analisar todas elas, quando do controle do ato considerado abusivo. Em consequência, tais sub-regras se relacionariam de modo subsidiário, sendo que a análise da necessidade só seria exigível se a questão ainda não tivesse sido resolvida pela adequação; e a análise da proporcionalidade em sentido estrito só seria imprescindível caso ainda o problema ainda não tivesse sido solucionado pela análise das regras da adequação e da necessidade.

\subsection{O postulado da razoabilidade}

Assim como a proporcionalidade, o postulado da razoabilidade funciona como mais um limite à discricionariedade administrativa. Como visto, a aplicação da proporcionalidade exige a relação de causalidade entre meio e fim, de tal sorte que, adotando-se o meio contribui-se para a promoção do fim. Já a razoabilidade não faz referência a uma relação de causalidade entre meio e fim, mas impõe os deveres de equidade, congruência, coerência e equivalência entre a imposição estabelecida e as consequências dela advindas (ÁVILA, 2008, p. 438-439).

O postulado da razoabilidade atua, portanto, sendo condutor dos seguintes valores: equidade, congruência, equivalência e coerência. A razoabilidade-equidade é utilizada como critério que exige a relação das normas gerais com as individualidades do caso concreto, seja mostrando sob qual perspectiva a norma deve ser aplicada, seja indicando em quais hipóteses o caso individual, em virtude de suas especificidades, deixa de se enquadrar na norma geral. A razoabilidade-congruência exige uma vinculação das normas jurídicas com o mundo ao qual elas fazem referência, reclamando uma relação congruente entre a medida adotada e o fim que ela pretende atingir. A razoabilidade-equivalência é utilizada como critério que exige a relação de equivalência entre duas grandezas, como ocorre no caso da exigência de correspondência entre a pena e a culpa, ou entre a taxa e o serviço público prestado. Por fím, a razoabilidade-coerência é diretriz que exige a consistência entre os elementos constantes de uma regra jurídica, proibindo a validade de normas que instituem deveres contraditórios ou sem qualquer sentido 
prático (ÁVILA, 2008, p. 425).

A razoabilidade opera, portanto, no balizamento entre o critério e a medida adotados no ato interpretado, na busca do dever de equidade, congruência ou de equivalência. Por isso, enquanto a proporcionalidade assume uma feição mais objetiva, a qual se expressa nos postulados da adequação, da necessidade e da proporcionalidade no sentido estrito, quando da análise da relação meio-fim do ato jurídico posto em exame, a razoabilidade se expressa em termos mais subjetivos, operando no campo hermenêutico na verificação da sintonia entre o critério e a medida adotados no ato jurídico examinado (LOBO, 2005, p. 252).

Assim, enquanto a razoabilidade tem uma função negativa - não ultrapassar os limites do juridicamente aceitável -, a proporcionalidade teria uma função positiva, qual seja, a de demarcar os limites, indicando como se mantém dentro deles (LOBO, 2005, p. 245).

Portanto, os postulados da razoabilidade e da proporcionalidade expressam construções jurídicas diversas. Pode-se admitir que eles têm objetivos semelhantes, mas isso não autoriza o tratamento de ambos como sinônimos (SILVA, 2002, p. 27). De todo o modo, revelam-se apropriados para avaliarem a validade jurídica de deveres instrumentais instituídos, com o fito de coibir excessos da administração e do legislador.

\subsection{A razoabilidade e a proporcionalidade como limites à imposição de deveres instrumentais}

São diversas as questões de índole tributária cuja natureza permite aplicações concretas dos postulados em estudo. Como exemplos, Rogério Leite Lobo (2005, p. 249-250), utilizando-se da lição de diversos autores, lista, entre outras, as seguintes: sanções tributárias, no sentido de que a gradação das multas pecuniárias impingidas aos contribuintes guarde relação de proporcionalidade e razoabilidade com a infração cometida; valor das taxas, na medida em que a exigência pelo ente tributante de valores pecuniários desproporcionais ao efetivo custeio das atividades exercidas vai de encontro aos postulados da proporcionalidade e da razoabilidade; princípio da capacidade contributiva e planejamento tributário, no sentido de que quando em cotejo com as regras antielisivas, o princípio da capacidade contributiva exige que a liberdade de planejamento tributário seja garantida com o permeio dos cânones da proporcionalidade e da razoabilidade. 
Além dessas aplicações, os deveres instrumentais impostos aos contribuintes podem, também, serem confrontados com os referidos postulados. Nesse sentido, Tércio Sampaio Ferraz Jr. (2005, p. 721) afirma que como a principal característica dessas obrigações está na instrumentalidade para o controle do cumprimento das obrigações principais, elas também se sujeitam à relação entre o meio escolhido e o fim visado, que é o ponto nuclear para o exame de sua consistência jurídica.

Ressalta o autor que, para apreciar a imposição de um dever instrumental sob tal critério, primeiramente deve-se verificar sua necessidade para o controle da obrigação tributária principal. Como exemplo de necessidade, o autor cita a imposição de instrumentos de controle em termos de aproveitamento de técnicas modernas, capazes de facilitar a fiscalização e a arrecadação, em um setor marcado pela sonegação de tributos, mormente quando se comprova que os meios usuais não conseguem sustar a evasão. Seria o caso do sistema Emissor de Cupom Fiscal em substituição às notas fiscais manuscritas, instituído para o controle do ICMS devido pelos estabelecimentos comerciais (FERRAZ JR., 2005, p. 724-725).

Mas só esta análise não é suficiente. Há de se verificar também a adequação do dever instrumental instituído ao fim colimado. Tome-se, como exemplo, o Sistema de Controle de Produção de Bebidas (Sicobe), o qual permite à Receita Federal controlar, em tempo real, todo o processo produtivo de bebidas no país, mediante a utilização de equipamentos e aparelhos para o controle, registro, gravação e transmissão das informações à sua base de dados. Além de contar a quantidade de produtos fabricados pelos estabelecimentos industriais, $\mathrm{o}$ Sicobe também efetua a identificação do tipo de produto, embalagem e sua respectiva marca comercial, que são base para cálculo dos tributos devidos, de acordo com a sistemática de tributação do setor implementada pela Lei $\mathrm{n}^{\circ} 11.727 / 2008$. Considerando que o setor de bebidas tem, historicamente, alta sonegação tributária, fato que, aliás, motivou a implantação do referido sistema, há de se entender que ele é adequado ao fim a que visa, qual seja, reduzir a sonegação tributária e, consequentemente, tornar mais justa a concorrência empresarial.

Por fim, há de se examinar ainda a proporcionalidade strictu sensu, no sentido de se observar se a intensidade da restrição a um direito do contribuinte é suficiente ou não para obstar o dever instrumental imposto. Um bom exemplo para se analisar a proporcionalidade em 
sentido estrito é o "regime especial de fiscalização", instituído pela Instrução Normativa $n^{\circ}$ 979/2009, de que trata o artigo 33 da Lei 9.430, de 27 de dezembro de 1996.

Tal regime consiste na aplicação de medidas que poderão ser aplicadas ao contribuinte, isolada ou cumulativamente, em relação a um ou mais tributos. São elas: manutenção de fiscalização ininterrupta no estabelecimento da empresa, inclusive com presença fiscal permanente de Auditores Fiscais; redução pela metade dos períodos de apuração e dos prazos de recolhimento dos tributos; utilização compulsória de controle eletrônico das operações realizadas e recolhimento diário dos respectivos tributos; exigência e comprovação sistemática do cumprimento das obrigações tributárias; controle especial da impressão e emissão de documentos comerciais e fiscais da movimentação financeira.

A norma estabelece que o regime será aplicado quando o contribuinte causar embaraço à fiscalização; recusar-se a fornecer informações solicitadas, ainda que seja intimado; impedir o acesso da fiscalização nas dependências da empresa; praticar crime contra a ordem tributária; realizar operações sujeitas a pagamento de tributos sem cadastrar-se na Receita Federal; praticar infração, de forma reiterada, à legislação tributária; comercializar mercadorias contrabandeadas e constituir interpostas pessoas que não sejam os verdadeiros sócios ou acionistas. Define ainda que os tributos não pagos durante a vigência do Regime serão acrescidos da multa de $150 \%$.

Percebe-se, claramente, que a implantação do regime especial de fiscalização, a depender da situação fática que o motivou, pode configurar uma verdadeira sanção indireta, que colide, frontalmente, com o direito fundamental ao livre exercício da atividade econômica. Como a proporcionalidade proíbe o excesso o objetivo visado com a imposição de um regime especial de fiscalização a determinado sujeito passivo pode não ter peso suficiente para justificar a restrição ao direito fundamental atingido.

Em suma, o "regime especial de fiscalização" pode ser necessário e adequado, mas é desproporcional em sentido estrito, situação que, por si só, configura uma violação ao postulado da proporcionalidade latu sensu..

Aliás, o Supremo Tribunal Federal já analisou situação semelhante. No caso, examinava-se a legitimidade constitucional de exigência estatal que erigiu a prévia satisfação de débito tributário como requisito necessário à outorga, pelo Poder Público, de autorização para a 
impressão de documentos fiscais.

Entendeu o STF que o litígio em causa envolvia a discussão em torno da possibilidade constitucional de o Poder Público impor restrições, ainda que fundadas em lei, destinadas a compelir o contribuinte inadimplente a pagar o tributo, mas que, por outro lado, possui um caráter gravoso e indireto de coerção estatal, por inviabilizar o exercício, pela empresa devedora, de atividade econômica lícita. Assim decidiu o referido Tribunal:

EMENTA: SANÇÕES POLÍTICAS NO DIREITO TRIBUTÁRIO. INADMISSIBILIDADE DA UTILIZAÇÃO, PELO PODER PÚBLICO, DE MEIOS GRAVOSOS E INDIRETOS DE COERÇÃO ESTATAL DESTINADOS A COMPELIR O CONTRIBUINTE INADIMPLENTE A PAGAR O TRIBUTO (SÚMULAS 70, 323 E 547 DO STF). RESTRIÇÕES ESTATAIS, QUE, FUNDADAS EM EXIGÊNCIAS QUE TRANSGRIDEM OS POSTULADOS DA RAZOABILIDADE E DA PROPORCIONALIDADE EM SENTIDO ESTRITO, CULMINAM POR INVIABILIZAR, SEM JUSTO FUNDAMENTO, O EXERCÍCIO, PELO SUJEITO PASSIVO DA OBRIGAÇÃO TRIBUTÁRIA, DE ATIVIDADE ECONÔMICA OU PROFISSIONAL LÍCITA. LIMITAÇÕES ARBITRÁRIAS QUE NÃO PODEM SER IMPOSTAS PELO ESTADO AO CONTRIBUINTE EM DÉBITO, SOB PENA DE OFENSA AO "SUBSTANTIVE DUE PROCESS OF LAW". IMPOSSIBILIDADE CONSTITUCIONAL DE O ESTADO LEGISLAR DE MODO ABUSIVO OU IMODERADO. O PODER DE TRIBUTAR - QUE ENCONTRA LIMITAÇÕES ESSENCIAIS NO PRÓPRIO TEXTO CONSTITUCIONAL, INSTITUÍDAS EM FAVOR DO CONTRIBUINTE - "NÃO PODE CHEGAR À DESMEDIDA DO PODER DE DESTRUIR" (MIN. OROSIMBO NONATO, RDA 34/132). A PRERROGATIVA ESTATAL DE TRIBUTAR TRADUZ PODER CUJO EXERCÍCIO NÃO PODE COMPROMETER A LIBERDADE DE TRABALHO, DE COMÉRCIO E DE INDÚSTRIA DO CONTRIBUINTE. A SIGNIFICAÇÃO TUTELAR, EM NOSSO SISTEMA JURÍDICO, DO "ESTATUTO CONSTITUCIONAL DO CONTRIBUINTE". DOUTRINA. PRECEDENTES. RECURSO EXTRAORDINÁRIO CONHECIDO E PROVIDO. (STF, DJ 08/04/2005, RE 374981/RS. Rel. Ministro Celso de Mello). 
Quanto à razoabilidade, é necessário verificar se a medida adotada satisfaz os seus quatro aspectos: equidade, congruência, equivalência e coerência. Para analisá-los frente a um caso concreto, tome-se o exemplo do SPED (Sistema Público de Escrituração Digital). A ideia desse sistema é a de que os contribuintes disponibilizem todas as informações contábeis e fiscais em um sistema virtual, que municiará a União e os Estados, eletronicamente, com toda a contabilidade do sujeito passivo, propiciando-lhe um controle online e permanente de suas obrigações tributárias.

Uma importante questão importante relativa ao SPED, adequada à análise que ora se realiza, é a sua enorme complexidade. Para exemplificar, pegue-se o caso da EFD PIS/Cofins (Escrituração Fiscal Digital do PIS e da Cofins): o arquivo digital a ser transmitido tem cerca de 150 registros e mais de mil campos a serem informados. Sua forma de apresentação, as especificações técnicas do arquivo digital, as tabelas de códigos internas e suas regras de validação foram definidas pelo Ato Declaratório Executivo Cofis $n^{\circ}$ 37/2010, documento que possui 109 páginas explicando como devem ser preenchidas as informações.

Demonstra-se, assim, que a EFD PIS/Cofins não é um instrumento razoável, pois não é um meio congruente entre a medida adotada e o fim que pretende atingir. Afinal, o Estado repassa ao contribuinte os altos custos de desenvolvimento do sistema, sendo, porém, o grande beneficiado com essa nova sistemática. Além disso, tal sistema é tão complexo que elevará, em muito, a potencialidade dos sujeitos passivos sofrerem lançamentos tributários indevidos, em função do preenchimento errôneo das informações solicitadas. Saliente-se que todo o processamento do SPED será automatizado, o que retira do contribuinte a possibilidade de, durante o processo fiscalizatório, sanar os problemas nas informações preenchidas.

Relativamente aos outros critérios da razoabilidade, registre-se ainda que, no caso em análise, o juiz, ao meu juízo, pode aplicar a equidade, indicando que, em virtude das especificidades de um dado contribuinte, determinar que ele não está sujeito à sistemática da EFD PIS/Cofins. Assim, por exemplo, se um contribuinte demonstrar que não tem condições de arcar com os custos de desenvolvimento de um sistema para atender a tal demanda, poderia o juiz desenquadrá-lo de tal obrigação.

No que toda à razoabilidade-equivalência, critério que exige a 
relação de equivalência entre duas grandezas, entendo que in casu o critério não se aplica. No que tange à razoabilidade-coerência, diretriz que proíbe a validade de normas que instituem deveres contraditórios ou sem qualquer sentido prático, depreende-se que esse critério é atendido. Contudo, por violar, um dos elementos da razoabilidade - a congruência -, pode-se considerar que a EFD PIS/Cofins não satisfaz o postulado da razoabilidade.

Enfim, a análise dos referidos postulados ensejam um exame detalhado em todos os seus elementos. Só assim evitar-se-á seu uso de forma meramente retórica. Como salienta Virgílio Afonso da Silva (2002, p. 31), em inúmeras decisões, sempre que se queira afastar alguma conduta considerada abusiva, recorre-se à fórmula "à luz do princípio da proporcionalidade ou da razoabilidade, o ato deve ser considerado inconstitucional". Diz que, normalmente, as decisões judiciais que os utilizam não fazem nenhuma referência a algum processo racional de controle do ato questionado, nem mesmo um real cotejo entre os fins almejados e os meios utilizados.

Por derradeiro, para se demonstrar a utilização correta de tais valores numa decisão judicial, cite-se o julgamento pelo STF de lei que obrigava empresas vendedoras de botijões de gás utilizarem balanças em seus veículos transportadores. Vários foram os argumentos aduzidos pela inconstitucionalidade da lei: o meio foi considerado inadequado (a balança não seria adequada para pesagem de uma unidade de massa); foi considerado desnecessário (a verificação por amostragem seria um meio menos restritivo); e, por fim, desproporcional em sentido estrito (as desvantagens - aumento do preço do botijão, deslocamento do consumidor até o caminhão - foram considerados sem proporção às vantagens - incremento da proteção dos consumidores) (ÁVILA, 2008, p. 413).

\section{CONCLUSÃO}

Como visto, os postulados da proporcionalidade e da razoabilidade, no âmbito do Direito Tributário, servem de elementos de ponderação de valores plasmados na Constituição, sendo instrumentos de solução de litígios que envolvem um circunstancial confronto entre eles.

No caso em análise, esses litígios envolvem o conflito entre os poderes de fiscalização tributária e o seu fundamento da preponderância do interesse público e os direitos e garantias individuais dos 
contribuintes. Por isso, em cada caso concreto caberá ao intérprete identificar aqueles princípios postos em circunstancial oposição, para, então, buscar nos postulados da proporcionalidade e da razoabilidade a possível ponderação entre eles, trazendo como resultado o desfecho que se afigure o mais justo para o litígio (LOBO, 2005, p. 251).

Isso porque, a relação de tributação não é uma simples relação de poder. Como preceitua Hugo de Brito Machado, modernamente, a relação de tributação:

[...] é uma relação jurídica, embora seu fundamento seja a soberania do Estado. Sua origem remota foi a imposição do vencedor sobre o vencido. Uma relação de escravidão, portanto. E essa origem espúria, infelizmente, às vezes ainda se mostra presente em nossos dias, nas práticas arbitrárias de autoridades da Administração Tributária (MACHADO, 2011, p. 27).

Nos dias atuais, entretanto, já não é razoável admitir-se a relação tributária como relação de poder. A ideia de liberdade, que preside nos dias atuais a própria concepção de Estado, há de estar presente, sempre, também na relação de tributação (MACHADO, 2011, p. 27).

Desse modo, se, por um lado, os poderes de fiscalização e arrecadação se estruturam no interesse público, por outro, as garantias constitucionais marcam os limites dentro dos quais deve-se alinhar o exercício dos poderes tributários.

No mesmo sentido, preconiza o Prof. James Marins que:

A atividade de fiscalização insere-se no conjunto das atividades que dizem respeito à Administração Tributária que necessariamente deve contar com mecanismos e instrumentos aptos a otimizar a arrecadação, mas sem que haja - jamais - o sacrifício das garantias individuais que alicerçam o ordenamento jurídico constitucional e tributário. (MARINS, J., 2010, p. 230).

Enfim, a tributação deve desenvolver-se dentro dos limites que a Carta Suprema traçou, fulminando o poder tributário absoluto do Estado. Por isso, os conflitos resultantes entre o poder estatal de fiscalizar e arrecadar e os direitos e garantias constitucionais dos contribuintes devem ser resolvidos pela ponderação dos princípios em face da situação fática, de maneira a proporcionar a solução mais razoável e proporcional 
para o caso em choque.

\section{REFERÊNCIAS}

ÁVILA, Humberto. Sistema constitucional tributário. São Paulo: Saraiva, 2008.

BRASIL. Superior Tribunal de Justiça. Recurso Especial n. 1.145.525/SC, Brasília, DF, 17 de maio de 2010.

BRASIL. Supremo Tribunal Federal. Recurso Extraordinário 374.981/RS, Brasília, DF, 8 de abril de 2005.

CARRAZZA, Roque Antônio. Curso de direito constitucional tributário. 25. ed. São Paulo: Malheiros, 2009.

CARVALHO, Paulo de Barros. Curso de direito tributário. 21. ed. São Paulo: Saraiva, 2009.

CEZAROTI, Guilherme. Aplicação de multa pelo descumprimento de obrigações acessórias: razoabilidade e proporcionalidade em sua aplicação. Revista Dialética de Direito Tributário, São Paulo, n. 148, p. 49-63, jan. 2008.

DERZI, Misabel Abreu Machado. A fiscalização tributária em um Estado democrático de direito. Seminário fiscalização tributária: contexto, prática e tendências, 1999. Disponível em:

$<$ http://www.fazenda.gov.br/ucp/pnafe/cst/arquivos/Fisc-DemocMisabel.doc $>$. Acesso em: 8 mar. 2012.

FERRAZ JÚNIOR, Tércio Sampaio. Obrigação tributária acessória e limites de imposição: razoabilidade e neutralidade concorrencial do Estado. In: FERRAZ, Roberto. Princípios e limites da tributação. São Paulo: Quartier Latin, 2005, p. 717-725.

FERRAZO, Cristiano José. Os limites de imposição de obrigações acessórias no direito tributário brasileiro. 2006. $111 \mathrm{f}$. Dissertação (Mestrado em Direito) - Programa de Pós-Graduação em Direito Universidade Federal do Rio Grande do Sul, Porto Alegre, 2006. 
LOBO, Rogério Leite. Os princípios da proporcionalidade e da razoabilidade e o direito tributário. Revista de Direito Administrativo, Rio de Janeiro, n. 239, p. 241-255, jan/mar de 2005.

MACHADO, Hugo de Brito. Fato gerador da obrigação acessória.

Revista Dialética de Direito Tributário, São Paulo, n. 96, p. 29-35, set. 2003.

2011.

. Curso de direito tributário. 32. ed. São Paulo: Malheiros,

MARINS, James. Direito processual tributário brasileiro:

(administrativo e judicial). 5. ed. São Paulo: Dialética, 2010.

MARTINS, Ives Gandra da Silva. Obrigações acessórias tributárias e a disciplina jurídica da concorrência. In: FERRAZ, Roberto. Princípios e limites da tributação. São Paulo: Quartier Latin, 2005, p. 667-683.

MENDES, Gilmar. O princípio da proporcionalidade na jurisprudência do Supremo Tribunal Federal: novas leituras. Revista Diálogo Jurídico, Salvador, CAJ - Centro de Atualização Jurídica, v. 1, n. 5, agosto, 2001. Disponível em: <http://www.direitopublico.com.br>. Acesso em: 15 mar. 2012.

MITA, Enrico de. O princípio da capacidade contributiva. In: Ferraz, Roberto. Princípios e limites da tributação. São Paulo: Quartier Latin, 2005, p. 221-254.

NABAIS, José Casalta. Algumas reflexões sobre o actual estado fiscal. Revista Fórum de Direito Tributário, Belo Horizonte, v. 1, n. 4, jul. 2003. Disponível em: <http://bdjur.stj.jus.br/dspace/handle/2011/29477>. Acesso em: 17 nov. 2011.

SILVA, Virgílio Afonso da. O proporcional e o razoável. Revista dos Tribunais, São Paulo, n. 798, 2002, p. 23-50. 
